in vivo $34: 3225-3231(2020)$

doi:10.21873/invivo.12158

\title{
A Non-invasive Imageable GFP-expressing Mouse Model of Orthotopic Human Bladder Cancer
}

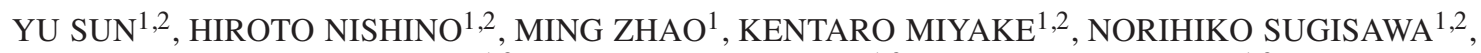 \\ JUN YAMAMOTO ${ }^{1,2}$, YOSHIHIKO TASHIRO ${ }^{1,2}$, SACHIKO INUBUSHI $^{1,2}$, \\ KAZUYUKI HAMADA ${ }^{1,2}$, GUANGWEI ZHU ${ }^{1,2}$, HYEIN LIM ${ }^{1,2}$ and ROBERT M. HOFFMAN ${ }^{1,2}$ \\ ${ }^{1}$ AntiCancer, Inc., San Diego, CA, U.S.A.; \\ ${ }^{2}$ Department of Surgery, University of California San Diego, San Diego, CA, U.S.A.
}

\begin{abstract}
Background/Aim: A more realistic mouse model of bladder cancer is necessary to develop effective drugs for the disease. Tumor models enhanced by bright fluorescent-reporter genes to follow the disease in real-time would enhance the ability to accurately predict the efficacy of various therapeutics on this particularly-malignant human cancer. Materials and Methods: A highly-fluorescent green fluorescent protein (GFP)expressing bladder cancer model was orthotopically established in nude mice using the UM-UC-3 human bladder-cancer cell line (UM-UC-3-GFP). Fragments from a subcutaneous tumor of UM-UC-3-GFP were surgically implanted into the nude mouse bladder. Non-invasive and intra-vital fluorescence imaging was obtained with a simple imaging box. Results: The GFP-expressing orthotopic bladder tumor was imaged in realtime non-invasively as well as intra-vitally, with the two methods correlating at $r=0.99$. Conclusion: This is the first noninvasive-fluorescence-imaging orthotopic model of bladder cancer and can be used for rapidly screening novel effective agents for this recalcitrant disease.
\end{abstract}

Transitional-epithelium-derived bladder cancer is a recalcitrant disease. Our laboratory has developed an intacttissue method of orthotopic implantation of human tumors in nude mice termed surgical orthotopic implantation (SOI) (1). We developed an SOI mouse model of bladder cancer thirty years ago, which was the first to show metastases (2-4). Orthotopic models are more accurate cancer models than subcutaneous xenografts, which typically do not metastasize

This article is freely accessible online.

Correspondence to: Robert M. Hoffman, AntiCancer, Inc, 7917 Ostrow St, San Diego, CA, 92111, U.S.A. Tel: +1 8586542555, email: all@anticancer.com

Key Words: Bladder cancer, nude mice, orthotopic, GFP, imaging, non-invasive.
(5) and may respond differently to chemotherapeutic agents than in situ human disease (6). By accurately modeling human disease, orthotopic xenograft models may be used to develop and test various therapeutics and predict their activity on human cancer. For an orthotopic model to fully express its malignant potential, SOI of intact tissue is necessary, as opposed to orthotopic injection of cells $(2,7,8)$.

Our laboratory pioneered the in vivo use of the green fluorescent protein (GFP) to establish orthotopic fluorescent human cancer xenografts (9-15). In these models, the GFP gene is stably transduced into human cancer cell lines, which subsequently express GFP at high levels in vitro and in vivo, including primary and metastatic tumors. We have used this technology to engineer fluorescent orthotopic models of pancreatic cancer (9-11), as well as lung cancer (12), prostate cancer (13), colon cancer (16), sarcoma (17), stomach cancer (18), melanoma (19), glioma (20), nasopharyngeal cancer (21), liver metastases (22), head and neck cancer (23) and breast cancer (24). We also developed an orthotopic model of GFP-expressing bladder cancer that could be imaged intra-vitally (15).

Recently, Naito et al. reported a cell-injection orthotopic model of UM-UC-3 bladder cancer (25). Huebner et al. have developed a luciferase-expressing cell-injection orthotopic model of UM-UC-3 bladder cancer (26). However, luciferase produces a weak signal that cannot be imaged and relies on expensive and cumbersome photon counting $(27,28)$. In the present study, we developed a new GFP-expressing SOI model of human bladder cancer using UM-UC-3-GFP that could be imaged non-invasively, without anesthesia, with a simple footpedal-controlled light box, as well as intra-vitally imaged.

\section{Materials and Methods}

Mice. Female nude nu/nu mice 6-8 weeks (AntiCancer, Inc., San Diego, CA, USA) were used. An inspection was performed to ensure their suitability for the study before cancer-cell implantation. The animals were maintained in a HEPA-filtered environment in a Micro-VENT full-ventilation rodent housing system (Allentown 

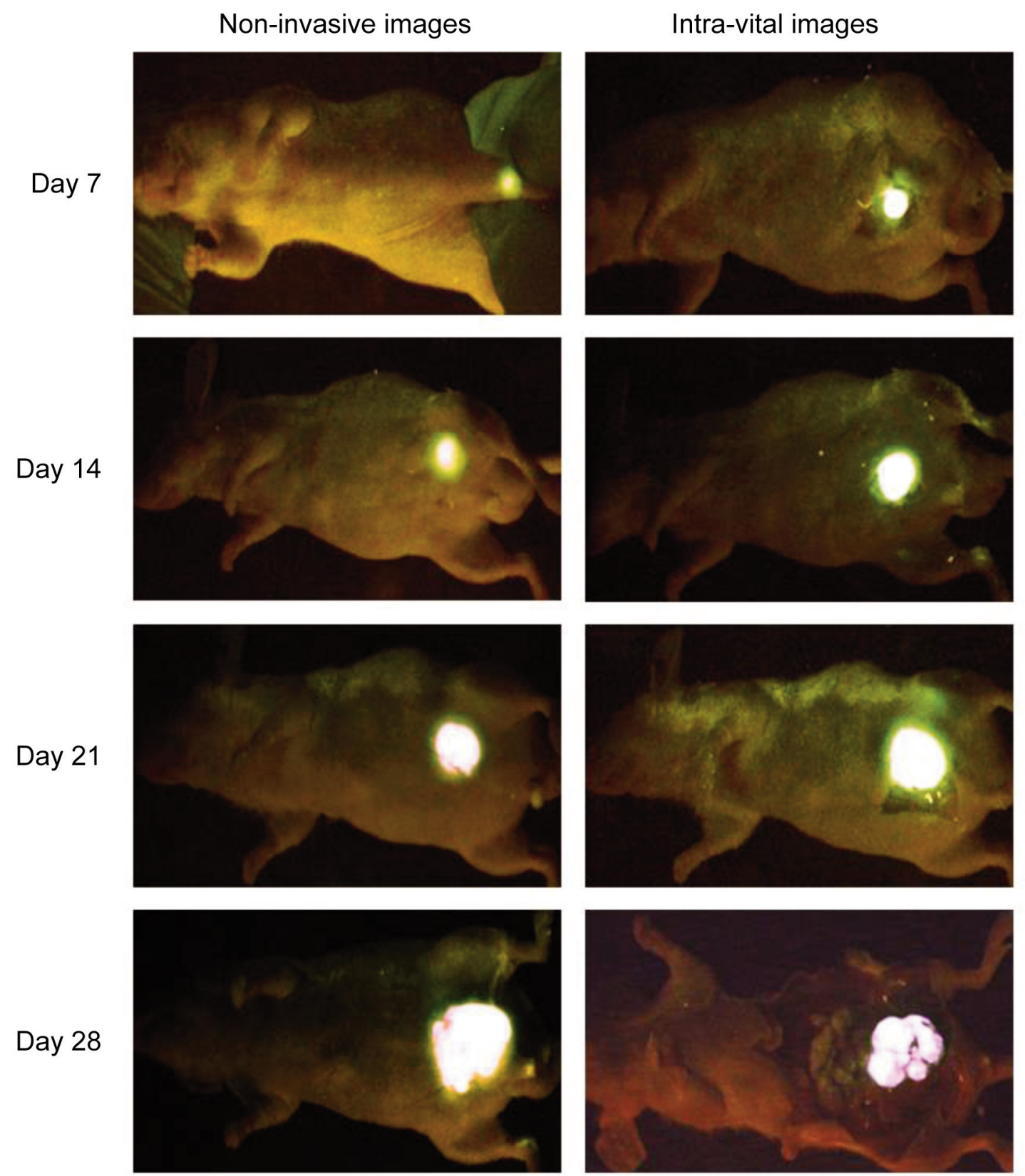

Figure 1. Comparison of non-invasive and invasive (intra-vital) imaging of the orthotopic bladder tumor.

Caging Equipment Co., Allentown, NJ, USA) at AntiCancer, Inc. Animal-room controls were set to maintain temperature and relative humidity at $22^{\circ} \mathrm{C} \pm 2^{\circ} \mathrm{C}$ and $55 \% \pm 15 \%$, respectively. The rooms were lit by artificial light for $12 \mathrm{~h}$ each day. Cages and bedding were autoclaved. Water was purified by Milli-Q Biocel System (Millipore, Billerica, MA, USA), autoclaved and supplied ad libitum to each cage via water bottles. Autoclavable rodent diet 5010 was obtained from PMI Nutrition International Inc. (Brentwood, MO, USA). All animals were weighed using an electronic balance (Spectrum; APX-203, Gardena, CA, USA) and given a clinical examination to ensure that they were in good condition. All animal studies were conducted with an AntiCancer Institutional Animal Care and Use Committee (IACUC)-protocol approved for this study and in accordance with the principles and procedures outlined in the National Institutes of Health Guide for the Care and Use of Animals under Assurance Number A3873-1 (29).

Cell line. UM-UC-3-GFP cells (AntiCancer Inc.) were cultured in Dulbecco's modified Eagle's medium supplemented with $1 \%$ penicillin and streptomycin (Invitrogen) and 10\% fetal bovine serum 
A

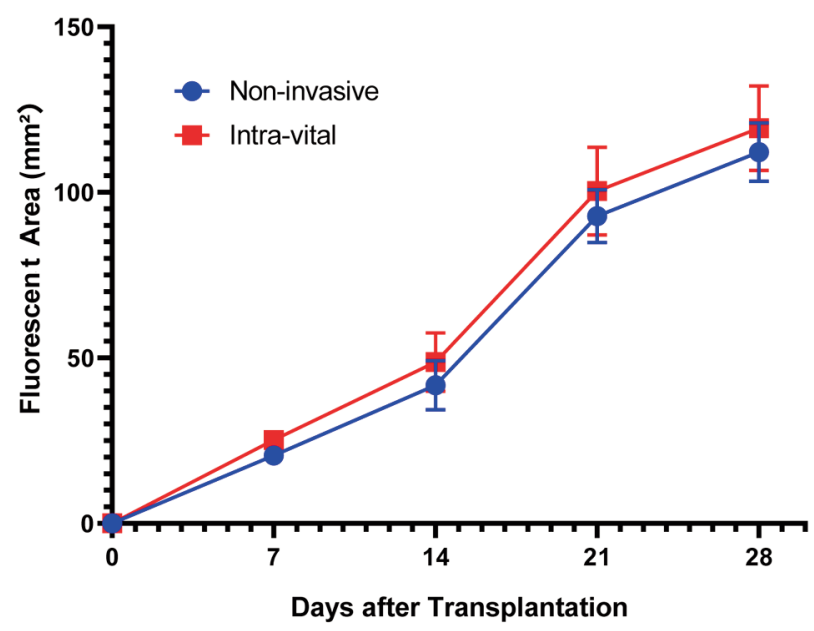

B

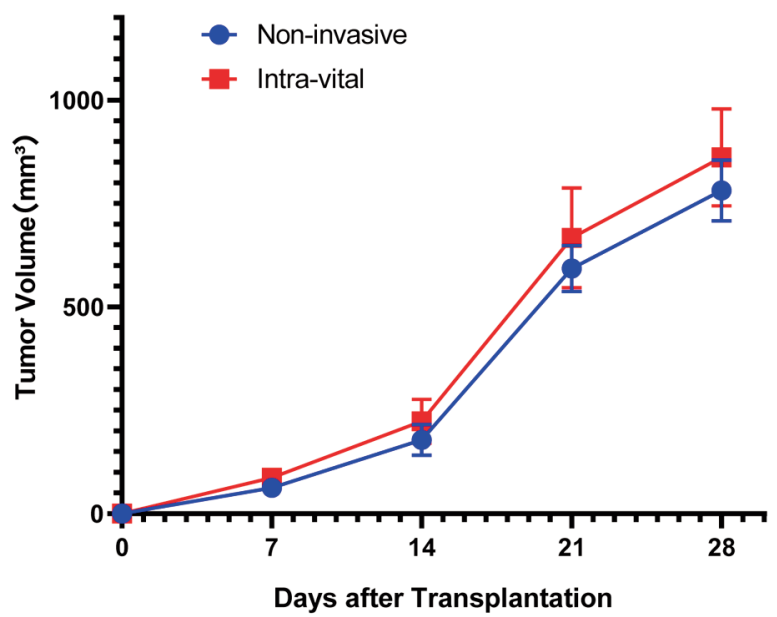

Figure 2. Orthotopic bladder-cancer growth curves comparing non-invasive and intra-vital imaging. (A) Tumor growth monitored by fluorescent area; (B) Tumor growth monitored by volume.

(Sigma-Aldrich). The cells were incubated at $37^{\circ} \mathrm{C}$ in a humidified atmosphere of $5 \% \mathrm{CO}_{2}$ in air.

Orthotopic mouse model. UM-UC-3-GFP cells $\left(5 \times 10^{6}\right)$ in $100 \mu \mathrm{l}$ PBS were initially subcutaneously injected on both flanks in nude mice. After subcutaneous tumor growth, the tumors were excised and divided into small fragments and 5 mice were implanted orthotopically with one $2 \mathrm{~mm}^{3}$ fragment of tumor on the bladder using SOI in each mouse.

The establishment of a bladder cancer orthotopic model was as follows: A $5 \mathrm{~mm}$ incision was made on the lower-abdominal area and the bladder was exposed from the intra-abdominal space. Then, a $2 \mathrm{~mm}^{3}$ tumor fragment was implanted on the dome of the bladder using 7-0 surgical sutures. The bladder was returned to the intraabdominal space and the incision was closed in one layer using 6-0 surgical sutures.

Fluorescence imaging. Tumor size, using both non-invasive and intra-vital imaging, was measured using the real-time fluorescence imaging FluorVivo system and its software (INDEC Systems, Santa Clara, CA, USA). Non-invasive imaging was recorded through the intact skin. Invasive intra-vital imaging was recorded during laparotomy. Non-invasive imaging and intra-vital imaging were evaluated on days 7, 14, 21 and 28 after implantation. All the mice were euthanized on day 28 . At autopsy, the abdominal cavity was opened to image the primary tumor and metastasis.

Tumor-size and body-weight measurement. Tumor size was measured once a week using the FluorVivo. Body weight was recorded using an electronic scale. The approximate tumor volume was calculated by measuring the perpendicular minor dimension (W) and major dimension (L). Approximate tumor volume $\left(\mathrm{mm}^{3}\right)$ was calculated with the formula $(\mathrm{W} \times \mathrm{W} \times \mathrm{L}) \times 1 / 2$. Fluorescence area was measured using Image J 1.52a software (National Institutes of Health).
Statistical analysis. Correlation was measured using the Pearson product-moment correlation coefficient: $p \leq 0.05$ was considered statistically significant.

\section{Results}

Tumor growth monitoring. Tumor progression was visualized both by non-invasive and intra-vital imaging (Figure 1).

Over 28 days, the mean fluorescence area increased from $20.5 \mathrm{~mm}^{2}$ to $112.1 \mathrm{~mm}^{2}$ in the non-invasive images and from $25.2 \mathrm{~mm}^{2}$ to $119.4 \mathrm{~mm}^{2}$ in the intra-vital images (Figure 2A).

Over 28 days, the mean tumor volume increased from $62.3 \mathrm{~mm}^{3}$ to $781.6 \mathrm{~mm}^{3}$ in the non-invasive images and from $87.4 \mathrm{~mm}^{3}$ to $862.0 \mathrm{~mm}^{3}$ in the intra-vital images (Figure 2B).

Metastasis incidence. All the mice were sacrificed at the end of the study on day 28. Three of 5 mice had metastasis, as examined by necropsy. Among the 3 mice which had metastasis, 3 mice had mesenteric lymph-node metastasis, 2 mice had lumber lymph-node metastasis, testicular metastasis and pancreatic metastasis and 1 mouse had liver metastasis (Figure 3).

Correlation of non-invasive and intra-vital imaging. There was a positive correlation between non-invasive and invasive imaging for both tumor volume $(\mathrm{R}=0.9949, p<0.0001)$ and fluorescent area $(\mathrm{R}=0.9971, p<0.0001)$ (Figure 4).

There was a positive correlation between tumor volume and fluorescent area for both non-invasive imaging $(\mathrm{R}=0.9951, p<0.0001)$ and intra-vital imaging $(\mathrm{R}=0.9939$, $p<0.0001$ ) (Figure 5). 


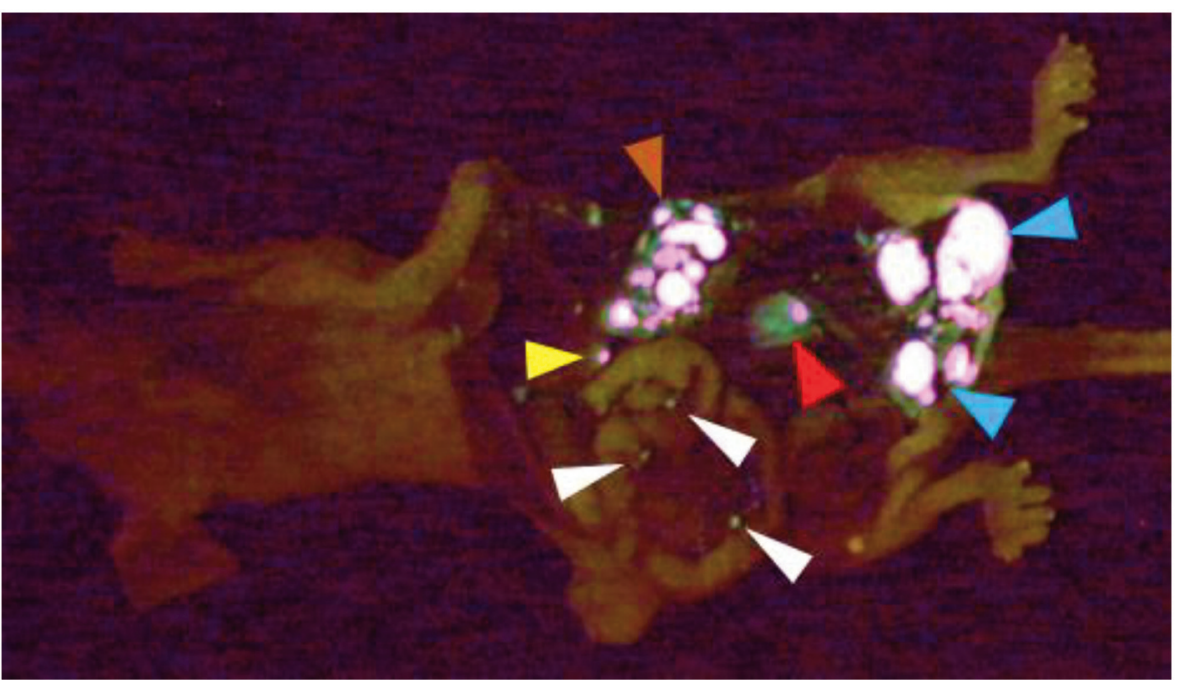

Figure 3. Representative images of metastasis at autopsy. Yellow arrows: liver metastasis; Orange arrow: pancreatic metastasis; Red arrow: lumbar lymph-node metastasis; Blue arrows: testicular metastasis; White arrows: mesenteric lymph-node metastasis.

A

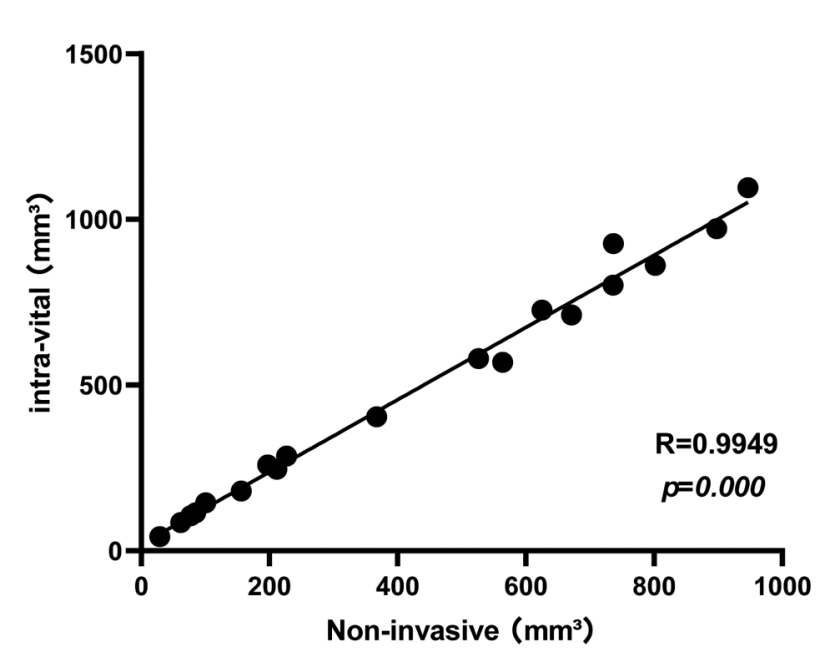

B

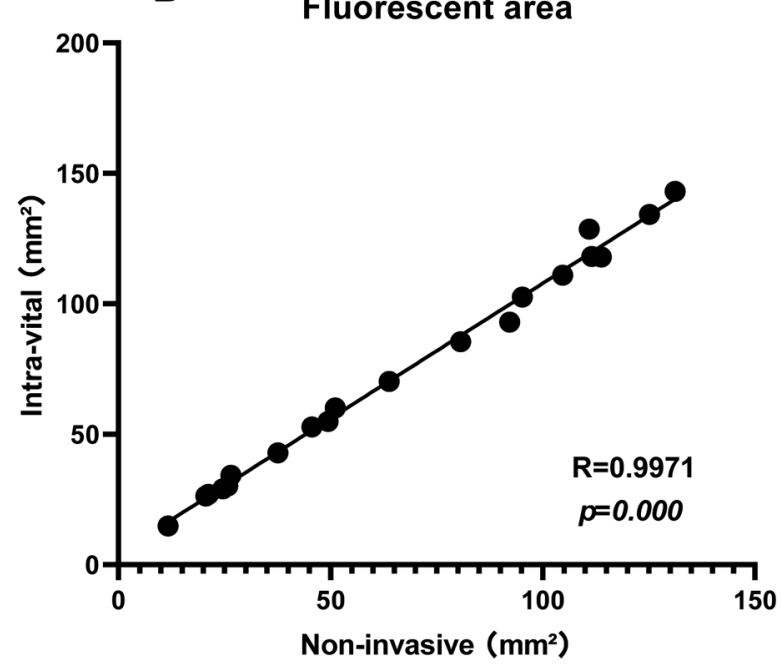

Figure 4. Correlation of tumor size between non-invasive and intra-vital imaging. (A) Comparison of non-invasive and intra-vital tumor volume. $R=0.9949, p<0.0001 ;(B)$ Comparison of non-invasive and intra-vital fluorescent area. $R=0.9971, p<0.0001$.

Body weight monitoring. The mean body weight decreased gradually during the experimental period due to cachexia because of the orthotopic bladder cancer and metastasis. The body-weight ratio is shown in Figure 6. The final bodyweight ratio (day 28/day 1) was $0.89 \pm 0.21$.

\section{Discussion}

To the best of our knowledge, this study is the first to report a non-invasive fluorescence-imaging orthotopic bladdercancer mouse model.
We were the first to report that tumor fluorescence enables real-time, sequential whole-body imaging and quantification of tumor burden without the need for anesthesia, laparotomy, contrast agents, or invasive procedures using fluorescent proteins $(14,27)$. The visualized area of fluorescence emitted by the internally-implanted tumors correlated significantly with tumor volume, as calculated using standard measurements obtained at autopsy (30). Tumor weight also correlated with tumor fluorescence (31).

The cellular orthotopic methods of bladder cancer described by Huebner et al. (26) and Naito et al. (25) where 


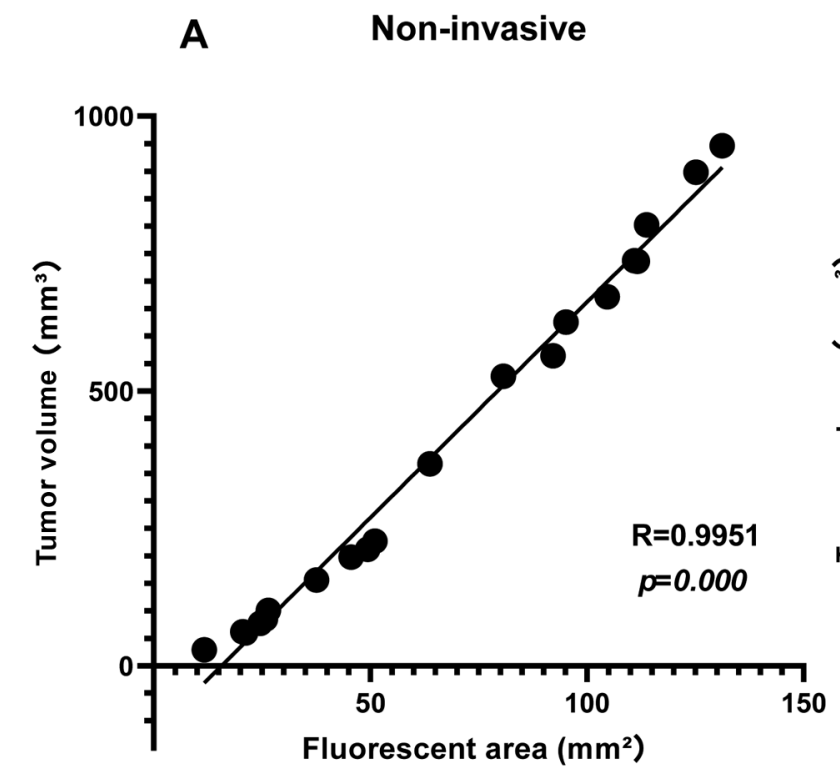

B

Intra-vital

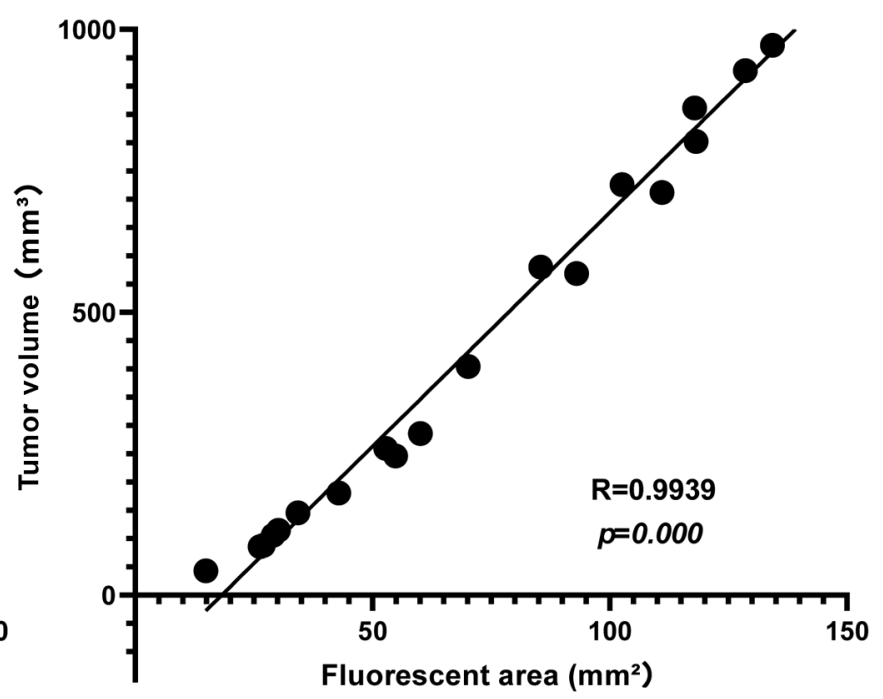

Figure 5. Correlation of tumor volume and fluorescent area. (A) Comparison of tumor volume and fluorescent area in non-invasive images. $R=0.9949, p<0.0001 ;(B)$. Comparison of tumor volume and fluorescent area in intra-vital images. $R=0.9939, p<0.0001$.

cancer cells were installed in the bladder whose inner surface was previously modified, resulted in inconsistent models. The present report describes a much simpler and reproducible model of suturing tumor fragments on the bladder. A luciferase-expressing orthotopic bladder-cancer model was previously reported by Huebner et al. (26). However, luciferase expression is too weak for imaging and only allows photon counting, which requires expensive and cumbersome equipment (27).

Our improved GFP-expressing orthotopic bladder cancer mouse model can be used to elucidate the therapeutic mechanisms of existing agents and to develop novel therapeutics for recurrent bladder cancer. Non-invasive imaging, using very simple equipment, will allow rapid screening to identify effective new agents.

\section{Conflicts of Interest}

None of the Authors declare any conflicts of interest related to this study. AntiCancer Inc. offers orthotopic mouse models of cancer for contract research.

\section{Authors' Contributions}

YS designed the study; YS, HN, KM, NS, JY, YT, SI, KH, HL performed the experiments; YS, GZ analyzed the data; YS, HN drafted the manuscript; MZ, RMH revised the manuscript; RMH supervised the study.

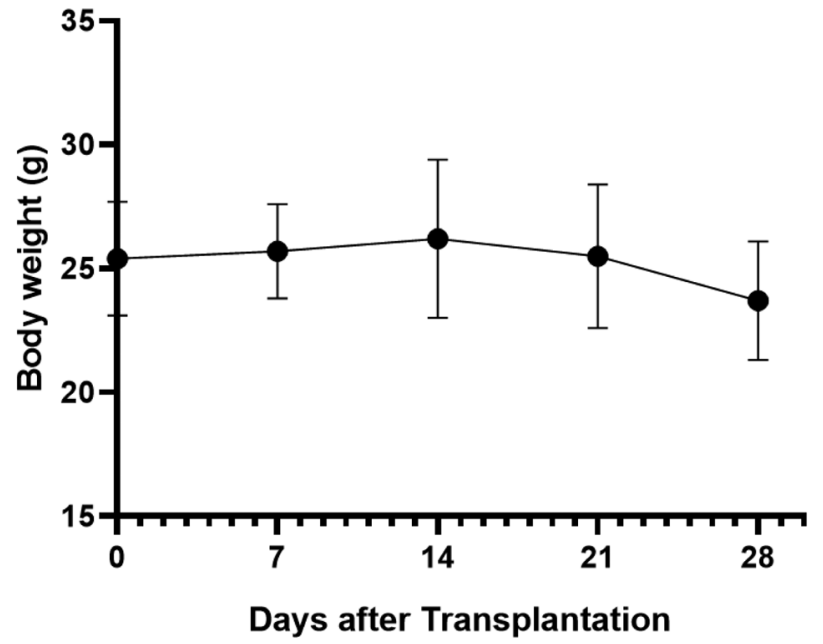

Figure 6. Time course of body-weight ratio. A stable body weight was observed in the first three weeks after tumor implantation, and a decrease in body weight in the last week was due to cachexia.

\section{References}

1 Fu XY, Besterman JM, Monosov A and Hoffman RM: Models of human metastatic colon cancer in nude mice orthotopically constructed by using histologically intact patient specimens. Proc Natl Acad Sci USA 88(20): 9345-9349, 1991. PMID: 1924398. DOI: $10.1073 /$ pnas.88.20.9345 
2 Fu XY, Theodorescu D, Kerbel RS and Hoffman RM: Extensive multi-organ metastasis following orthotopic onplantation of histologically-intact human bladder carcinoma tissue in nude mice. Int J Cancer 49(6): 938-939, 1991. PMID: 1959996. DOI: 10.1002/ijc.2910490623

$3 \mathrm{Fu} \mathrm{X}$ and Hoffman RM: Human RT-4 bladder carcinoma is highly metastatic in nude mice and comparable to RAS-Htransformed RT-4 when orthotopically onplanted as histologically intact tissue. Int J Cancer 51(6): 989-991, 1992. PMID: 1639544. DOI: 10.1002/ijc.2910510625

4 Chang SG, Kim JI, Jung JC, Rho YS, Lee KT, An Z, Wang X and Hoffman RM: Antimetastatic activity of the new platinum analog [Pt(cis-dach) (DPPE).2NO3] in a metastatic model of human bladder cancer. Anticancer Res 17(5A): 3239-3242, 1997. PMID: 9413154.

5 Kyriazis AP, DiPersio L, Michael GJ, Pesce AJ and Stinnett JD: Growth patterns and metastatic behavior of human tumors growing in athymic mice. Cancer Res 38(10): 3186-3190, 1978. PMID: 688209 .

6 Kuo TH, Kubota T, Watanabe M, Furukawa T, Kase S, Tanino H, Saikawa Y, Ishibiki K, Kitajima M and Hoffman RM: Sitespecific chemosensitivity of human small-cell lung carcinoma growing orthotopically compared to subcutaneously in scid mice: The importance of orthotopic models to obtain relevant drug evaluation data. Anticancer Res 13(3): 627-630, 1993. PMID: 8391244.

7 Furukawa T, Fu X, Kubota T, Watanabe M, Kitajima M and Hoffman RM: Nude mouse metastatic models of human stomach cancer constructed using orthotopic implantation of histologically intact tissue. Cancer Res 53(5): 1204-1208, 1993. PMID: 8439965.

8 An Z, Jiang P, Wang X, Moossa AR and Hoffman RM: Development of a high metastatic orthotopic model of human renal cell carcinoma in nude mice: Benefits of fragment implantation compared to cell-suspension injection. Clin Exp Metastasis 17(3): 265-270, 1999. PMID: 10432012. DOI: 10.1023/a:1006654600095

9 Bouvet M, Wang J, Nardin SR, Nassirpour R, Yang M, Baranov E, Jiang P, Moossa AR and Hoffman RM: Real-time optical imaging of primary tumor growth and multiple metastatic events in a pancreatic cancer orthotopic model. Cancer Res 62(5): 1534-1540, 2002. PMID: 11888932.

10 Bouvet M, Yang M, Nardin S, Wang X, Jiang P, Baranov E, Moossa AR and Hoffman RM: Chronologically-specific metastatic targeting of human pancreatic tumors in orthotopic models. Clin Exp Metastasis 18(3): 213-218, 2000. PMID: 11315094. DOI: 10.1023/a:1006767405609

11 Sun FX, Tohgo A, Bouvet M, Yagi S, Nassirpour R, Moossa AR and Hoffman RM: Efficacy of camptothecin analog DX-8951f (exatecan mesylate) on human pancreatic cancer in an orthotopic metastatic model. Cancer Res 63(1): 80-85, 2003. PMID: 12517781

12 Rashidi B, Yang M, Jiang P, Baranov E, An Z, Wang X, Moossa AR and Hoffman RM: A highly metastatic lewis lung carcinoma orthotopic green fluorescent protein model. Clin Exp Metastasis 18(1): 57-60, 2000. PMID: 11206839. DOI: 10.1023/a:10265 96131504

13 Yang M, Jiang P, Sun FX, Hasegawa S, Baranov E, Chishima T, Shimada H, Moossa AR and Hoffman RM: A fluorescent orthotopic bone metastasis model of human prostate cancer. Cancer Res 59(4): 781-786, 1999. PMID: 10029062.
14 Yang M, Baranov E, Jiang P, Sun FX, Li XM, Li L, Hasegawa S, Bouvet M, Al-Tuwaijri M, Chishima T, Shimada H, Moossa AR, Penman and Hoffman RM: Whole-body optical imaging of green fluorescent protein-expressing tumors and metastases. Proc Natl Acad Sci U S A 97(3): 1206-1211, 2000. PMID: 10655509. DOI: 10.1073/pnas.97.3.1206

15 Zhou JH, Rosser CJ, Tanaka M, Yang M, Baranov E, Hoffman RM and Benedict WF: Visualizing superficial human bladder cancer cell growth in vivo by green fluorescent protein expression. Cancer Gene Ther 9(8): 681-686, 2002. PMID: 12136429. DOI: $10.1038 /$ sj.cgt.7700489

$16 \mathrm{Fu} \mathrm{X}$, Herrera H, Kubota T and Hoffman RM: Extensive liver metastasis from human colon cancer in nude and scid mice after orthotopic onplantation of histologically-intact human colon carcinoma tissue. Anticancer Res 12(5): 1395-1397, 1992. PMID: 1444196.

17 Kiyuna T, Murakami T, Tome Y, Kawaguchi K, Igarashi K, Zhang Y, Zhao M, Li Y, Bouvet M, Kanaya F, Singh A, Dry S, Eilber FC and Hoffman RM: High efficacy of tumor-targeting Salmonella typhimurium A1-R on a doxorubicin- and dactolisib-resistant follicular dendritic-cell sarcoma in a patient-derived orthotopic xenograft PDOX nude mouse model. Oncotarget 7(22): 33046-33054, 2016. PMID: 27105519. DOI: 10.18632/oncotarget.8848

18 Yano S, Zhang Y, Miwa S, Tome Y, Hiroshima Y, Uehara F, Yamamoto M, Suetsugu A, Kishimoto H, Tazawa H, Zhao M, Bouvet M, Fujiwara T and Hoffman RM: Spatial-temporal FUCCI imaging of each cell in a tumor demonstrates locational dependence of cell cycle dynamics and chemoresponsiveness. Cell Cycle 13(13): 2110-2119, 2014. PMID: 24811200. DOI: $10.4161 / \mathrm{cc} .29156$

19 Yamamoto M, Zhao M, Hiroshima Y, Zhang Y, Shurell E, Eilber FC, Bouvet M, Noda M and Hoffman RM: Efficacy of tumor-targeting Salmonella A1-R on a melanoma patient-derived orthotopic xenograft (PDOX) nude-mouse model. PLoS One 11(8): e0160882, 2016. PMID: 27500926. DOI: 10.1371/journal.pone.0160882

20 Momiyama M, Hiroshima Y, Suetsugu A, Tome Y, Mii S, Yano S, Bouvet M, Chishima T, Endo I and Hoffman RM: Enhanced resection of orthotopic red-fluorescent-protein-expressing human glioma by fluorescence-guided surgery in nude mice. Anticancer Res 33(1): 107-111, 2013. PMID: 23267134.

21 Liu T, Ding Y, Xie W, Li Z, Bai X, Li X, Fang W, Ren C, Wang S, Hoffman RM and Yao K: An imageable metastatic treatment model of nasopharyngeal carcinoma. Clin Cancer Res 13(13): 3960-3967, 2007. PMID: 17606730. DOI: 10.1158/10780432.CCR-07-0089

22 Murakami T, Hiroshima Y, Zhao M, Zhang Y, Chishima T, Tanaka K, Bouvet M, Endo I and Hoffman RM: Therapeutic efficacy of tumor-targeting Salmonella typhimurium A1-R on human colorectal cancer liver metastasis in orthotopic nudemouse models. Oncotarget 6(31): 31368-31377, 2015. PMID: 26375054. DOI: 10.18632 oncotarget.5187

23 Lee SE, Bairstow SF, Werling JO, Chaubal MV, Lin L, Murphy MA, DiOrio JP, Gass J, Rabinow B, Wang X, Zhang Y, Yang Z and Hoffman RM: Paclitaxel nanosuspensions for targeted chemotherapy - nanosuspension preparation, characterization, and use. Pharm Dev Technol 19(4): 438-453, 2014. PMID: 23617261. DOI: $10.3109 / 10837450.2013 .789911$

24 Yano S, Takehara K, Miwa S, Kishimoto H, Tazawa H, Urata Y, Kagawa S, Bouvet M, Fujiwara $\mathrm{T}$ and Hoffman RM: 
Fluorescence-guided surgery of a highly-metastatic variant of human triple-negative breast cancer targeted with a cancer-specific GFP adenovirus prevents recurrence. Oncotarget 7(46): 7563575647, 2016. PMID: 27689331. DOI: 10.18632/oncotarget.12314

25 Naito T, Higuchi T, Shimada Y and Kakinuma C: An improved mouse orthotopic bladder cancer model exhibiting progression and treatment response characteristics of human recurrent bladder cancer. Oncol Lett 19(1): 833-839, 2020. PMID: 31885717. DOI: $10.3892 /$ ol.2019.11172

26 Huebner D, Rieger C, Bergmann R, Ullrich M, Meister S, Toma M, Wiedemuth R, Temme A, Novotny V, Wirth MP, Bachmann M, Pietzsch J and Fuessel S: An orthotopic xenograft model for high-risk non-muscle invasive bladder cancer in mice: Influence of mouse strain, tumor cell count, dwell time and bladder pretreatment. BMC Cancer 17(1): 790, 2017. PMID: 29169339. DOI: $10.1186 / \mathrm{s} 12885-017-3778-3$

27 Hoffman RM: The multiple uses of fluorescent proteins to visualize cancer in vivo. Nat Rev Cancer 5(10): 796-806, 2005. PMID: 16195751. DOI: 10.1038/nrc1717

28 Hoffman RM and Yang M: Subcellular imaging in the live mouse. Nat Protoc 1(2): 775-782, 2006. PMID: 17406307. DOI: 10.1038/nprot.2006.109
29 Yang M, Reynoso J, Bouvet M and Hoffman RM: A transgenic red fluorescent protein-expressing nude mouse for color-coded imaging of the tumor microenvironment. J Cell Biochem 106(2): 279-284, 2009. PMID: 19097136. DOI: 10.1002/jcb.21999

30 Katz MH, Takimoto S, Spivack D, Moossa AR, Hoffman RM and Bouvet M: A novel red fluorescent protein orthotopic pancreatic cancer model for the preclinical evaluation of chemotherapeutics. J Surg Res 113(1): 151-160, 2003. PMID: 12943825. DOI: 10.1016/s0022-4804(03)00234-8

31 Hiroshima Y, Zhao M, Maawy A, Zhang Y, Katz MH, Fleming JB, Uehara F, Miwa S, Yano S, Momiyama M, Suetsugu A, Chishima T, Tanaka K, Bouvet M, Endo I and Hoffman RM: Efficacy of Salmonella typhimurium A1-R versus chemotherapy on a pancreatic cancer patient-derived orthotopic xenograft (PDOX). J Cell Biochem 115(7): 1254-1261, 2014. PMID: 24435915. DOI: $10.1002 /$ jcb.24769

Received August 2, 2020

Revised August 24, 2020

Accepted August 25, 2020 